\title{
Control of Microcrystal Structure of BaM Ferrite Films with Perpendicular Magnetic Anisotropy Deposited Using Plasma-Free Sputtering System
}

\author{
* Kenji NOMA, Nobuhiro MATSUSHITA, Shigeki NAKAGAWA and Masahiko NAOE \\ Dept. of Physical Electronics, Tokyo Institute of Technology, 2-12-1 O-okayama, Meguro, Tokyo 152, JAPAN. \\ *Fujitsu Ltd., 4-1-1 Kami-Kodanaka, Nakahara, Kawasaki 211-88, JAPAN.
}

\begin{abstract}
Ba ferrite films composed of microcrystallites with well $c$-axis orientation which seem to be suitable for perpendicular magnetic recording media were deposited using various sputtering apparatus and their microstructural and magnetic characteristics were investigated. The bombardment of energetic particles to the film during deposition and the elevation of substrate temperature strongly affected the growth prcess of $\mathrm{Ba}$ ferrite crystallites and the increase of perpendicular coercivity. The films deposited using Facing Targets Sputtering apparatus at the substrate temperature as low as $475{ }^{\circ} \mathrm{C}$ revealed that they were composed of nanocrystallites with the grain size below $100 \mathrm{~nm}$ and exhibited the coercivity of as high as $2.3 \mathrm{kOe}$.
\end{abstract}

\section{INTRODUCTION}

A magnetroprambite type of barium $(\mathrm{BaM})$ ferrite $(\mathrm{BaO} \cdot$ $6 \mathrm{Fe}_{2} \mathrm{O}_{3}$ ) films are hopeful materials for the perpendicular magnetic recording layer in rigid disks with high density because of their weak magnetic interactions among the small grains, high corrosion resistivity and hardness. The films composed of BaM ferrite crystallites with well $c$-axis orientation were deposited by various sputtering such as if Diode Sputtering (RFDS)[1] and dc Facing Targets Sputtering (DC-FTS) [2, 3]. It is very important for attain a high recording density above $20 \mathrm{Gbits} / \mathrm{inch}^{2}$ that the mean aspect ratio of Ba ferrite crystallites $r=\langle D\rangle_{(008)} /[D]_{(008)}$, where $\langle D\rangle_{(008)}$ corresponds to the mean crystallite size along $c$-axis and $[D]_{(008)}$ is that in $c$-plane, should be possibly larger because the demagnetization field $H_{\mathrm{d}}$ normal to the film surface and the media noise level are expected to reduce. In this study, the effects of bombardment of energetic of particles to the surface of the growing film and the elevation of substrate temperature on the ratio $r$ and perpendicular coercivity were investigated.

\section{EXPERIMENTS}

All the specimen films with the thickness of $200 \mathrm{~nm}$ were deposited on thermally oxidized $\mathrm{Si}\left(\mathrm{SiO}_{2} / \mathrm{Si}\right)$ wafers using various sputtering apparatus. The sintered ferrite plates with the composition of $\mathrm{BaO} \cdot n \mathrm{Fe}_{2} \mathrm{O}_{3}(n=4.0,5.5,6.5)$ were used as the sputtering targets and the mixture of $\mathrm{Ar}$ and $\mathrm{O}_{2}$ $\left(\mathrm{Ar}-\mathrm{O}_{2}\right)$ or Xe, $\mathrm{Ar}$ and $\mathrm{O}_{2}\left(\mathrm{Xe}-\mathrm{Ar}-\mathrm{O}_{2}\right)$ were used as sputtering gas. The microstructure of the surface of as-deposited films was observed with scanning electron microscopy (SEM). The crystallographic and magnetic characteristics of the films were evaluated by X-ray diffractometry (XRD) and using the vibrating sample magnetometer (VSM), respectively. The plasma parameters such as the plasma potential $V_{\mathrm{p}}$ and the floating potential at the substrate $V_{\mathrm{f}}$ were measured by Langmiur's single probe method.

\section{RESULTS AND DISCUSSION}

The energy of Ar ions bombarding the surface of the growing film $e\left(V_{\mathrm{p}}-V_{\mathrm{f}}\right)$ and the optimum substrate temperature $T_{\mathrm{s}}$ for depositing BaM ferrite films were different among three sputtering apparatus. In RFDS apparatus as shown Fig. 1(a), $e\left(V_{\mathrm{p}}-V_{\mathrm{f}}\right)$ reached to $38 \mathrm{eV}$, of which the value was large enough to cause the selective resputtering of Ba atoms physically adsorbed to the surface of the film, and it led to the remarkable decrease of Ba content in the film. In addition, $\gamma$-electrons ejected from the sputtering target were accelerated across the sheath region and they bombarded the film surface directly. The energy of electrons reaches to several hundreds $\mathrm{eV}$ and it caused the unexpected elevation of $T_{\mathrm{s}}$ and the deconstruction of crystal. BaM ferrite films with the composition of $\mathrm{BaO} \cdot 6.0 \mathrm{Fe}_{2} \mathrm{O}_{3}$ were deposited at $T_{\mathrm{s}}$ in the range from 620 to $760{ }^{\circ} \mathrm{C}$ using the target with a $\mathrm{Ba}$ excessive composition of $\mathrm{BaO} \cdot 4.0 \mathrm{Fe}_{2} \mathrm{O}_{3}$. The saturation magnetization $4 \pi M_{\mathrm{s}}$ and perpendicular coercivity $H_{\mathrm{c} \perp}$ of these films were about $2.0 \mathrm{kG}$ and $1.5 \mathrm{kOe}$, respectively, where the $4 \pi M_{\mathrm{s}}$ of the BaM ferrite single crystal is $4.8 \mathrm{kG}$.

Table I Specimen preparation and sputtering conditions

\begin{tabular}{lccc}
\hline $\begin{array}{l}\text { Sputtering } \\
\text { system (gas) }\end{array}$ & $\begin{array}{c}\text { RFDS } \\
\left(\mathrm{Ar}-\mathrm{O}_{2}\right)\end{array}$ & $\begin{array}{c}\text { DC-FTS } \\
\left(\mathrm{Ar}-\mathrm{O}_{2}\right)\end{array}$ & $\begin{array}{c}\text { DC-FTS } \\
\left(\mathrm{Xe}-\mathrm{Ar}-\mathrm{O}_{2}\right)\end{array}$ \\
\hline $\begin{array}{l}\text { Target } \\
\text { composition } n\end{array}$ & 4.0 & 5.5 & 6.5 \\
$\begin{array}{l}\text { Substrate } \\
\text { Temperature } T_{s}\end{array}$ & $550 \sim 700^{\circ} \mathrm{C}$ & $550 \sim 600^{\circ} \mathrm{C}$ & $475 \sim 600^{\circ} \mathrm{C}$ \\
$\begin{array}{l}\text { Total gas } \\
\text { pressure } P_{\text {toal }}\end{array}$ & $0.50 \mathrm{~Pa}$ & $0.27 \mathrm{~Pa}$ & $0.20 \mathrm{~Pa}$ \\
$\begin{array}{l}\text { Partial Xe } \\
\text { pressure } P_{\mathrm{xc}}\end{array}$ & - & - & $0.10 \mathrm{~Pa}$ \\
\hline
\end{tabular}




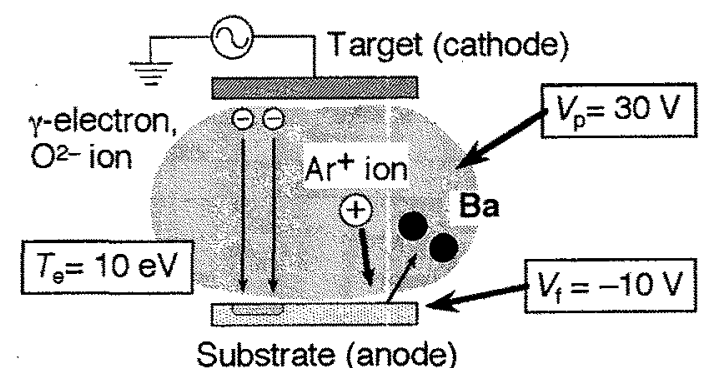

(a) RFDS

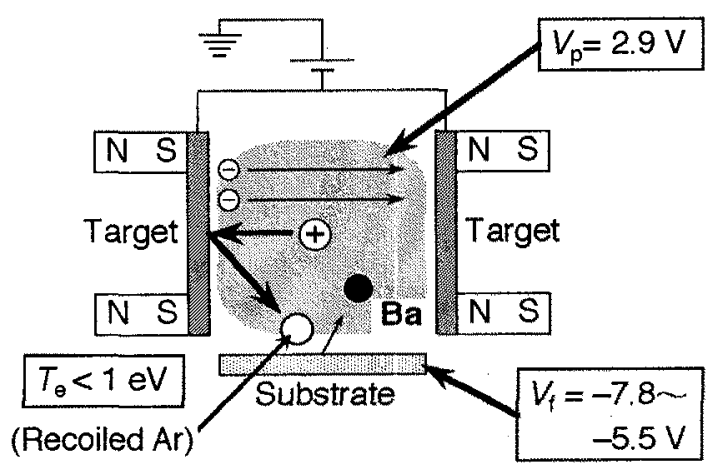

(b) DC-FTS

Fig. 1 The sputtering systems and their plasma distributions: $\left|V_{\mathrm{f}}\right|$ in Fig. 1(b) decreased with the increase of $P_{\text {Xe }}$.

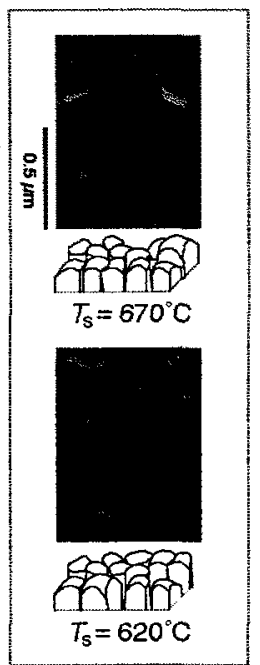

(a) RFDS

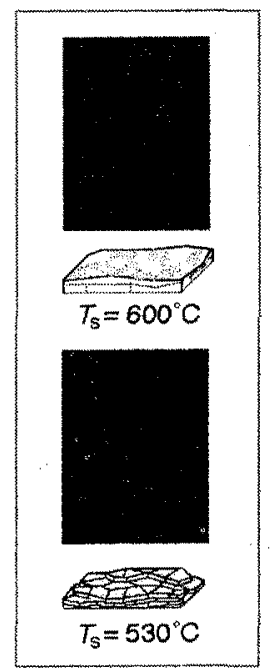

(b) DC-FTS $\left(\mathrm{Ar}-\mathrm{O}_{2}\right)$

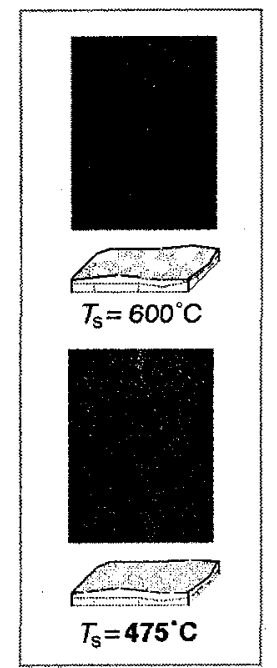

(c) DC-FTS (Xe-Ar-O
Fig. 2 SEM images of the films deposited using various sputtering apparatus.

In FTS apparatus as shown in Fig. 1(b), the plasma is confined almost perfectly between two facing targets and the bombardment of energetic charged particles such as $\gamma$ electrons, negative ions and Ar ones to the film surface was sufficiently suppressed. The $e\left(V_{\mathrm{p}}-V_{\mathrm{f}}\right)$ was as small as 10 $\mathrm{eV}$ and the films with well $c$-axis orientation were deposited

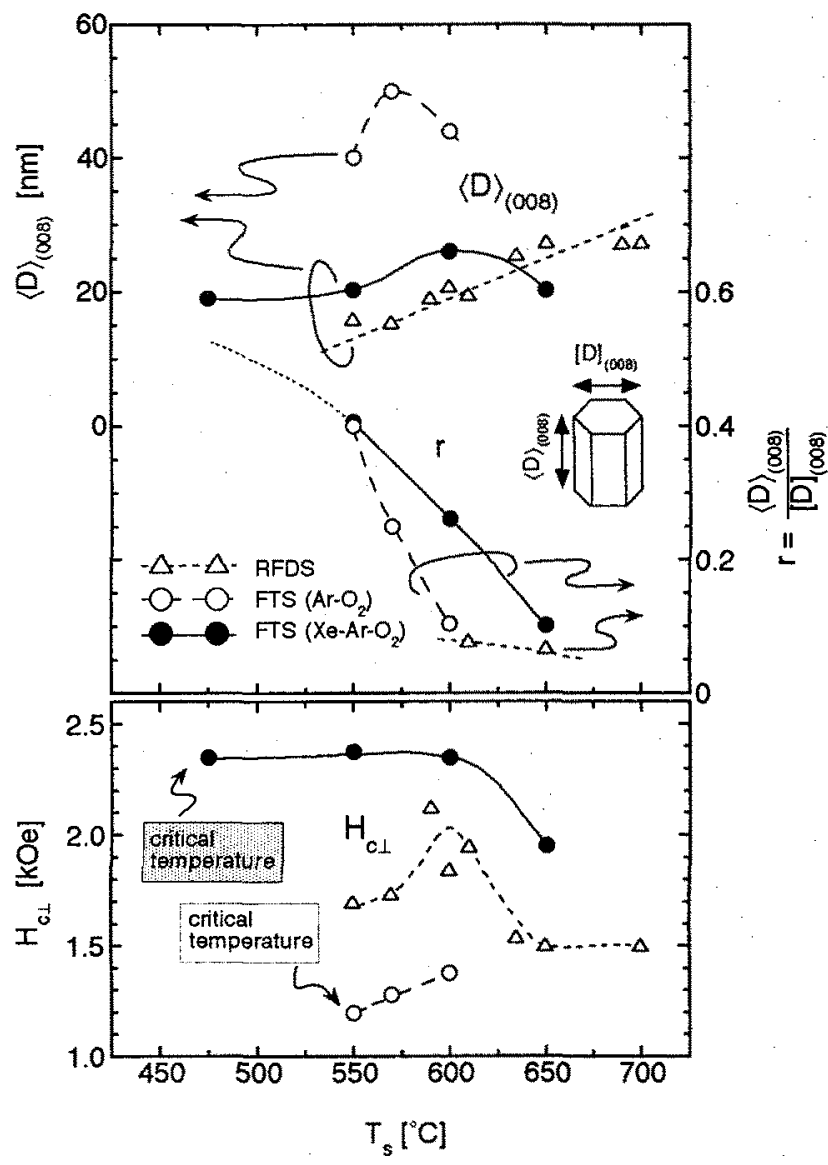

Fig. $3 T_{\mathrm{s}}$ dependences of $\langle D\rangle_{(008)}, r$ and $H_{\mathrm{cL}}$ of the films deposited using various sputtering apparatus.

at $T_{\mathrm{s}}$ of $555{ }^{\circ} \mathrm{C}$ using the target with a little Ba-excessive composition of $\mathrm{BaO} \cdot 5.5 \mathrm{Fe}_{2} \mathrm{O}_{3}$. However, the energetic $\mathrm{Ar}$ atoms recoiled from the targets seemed to bombard the film surface and to cause the worse surface smoothness. $4 \pi M_{\mathrm{s}}$ and $H_{\mathrm{c} \perp}$ of the film deposited at $T_{\mathrm{s}}$ of $555^{\circ} \mathrm{C}$ were $4.7 \mathrm{kG}$ and $1.2 \mathrm{kOe}$, respectively.

The bombardment of recoiled $\mathrm{Ar}$ atoms to the film surface was sufficiently suppressed using the mixture of Xe, Ar and $\mathrm{O}_{2}$ as sputtering gas. $\mathrm{Ba}$ ferrite films with well $c$-axis orientation and sufficiently large $4 \pi M_{\mathrm{s}}$ of $4.7 \mathrm{kG}$ and high $H_{\mathrm{c} \perp}$ of $2.3 \mathrm{kOe}$, respectively, were obtained at $T_{\mathrm{s}}$ as low as $475{ }^{\circ} \mathrm{C}$ using the targets with ' a little Fe-excessive composition of $\mathrm{BaO} \cdot 6.5 \mathrm{Fe}_{2} \mathrm{O}_{3}$. The value of $e\left(V_{\mathrm{p}}-V_{i}\right)$ decreased from 11 to $8 \mathrm{eV}$ with the addition of Xe into sputtering gas mixture.

Figure 2 shows the SEM images of these specimens. And, figure 3 shows the $T_{5}$ dependences of $\langle D\rangle_{(008)}$ calculated from the full with at half maximum (FWHM) of the BaM(008) peak in XRD diagrams, $r\left(\langle D\rangle_{(008)} /[D]_{(008)}\right)$ and $H_{\mathrm{c} \perp}$, where the grain diameter $[D]_{(008)}$ was determined from the SEM observation. The surface of the films shown in Fig. 2(a) reveal that the films deposited in RFDS apparatus were 
composed of the microcrystallites with $[D]_{(008)}$ above 300 $\mathrm{nm}$ and the surface smoothness was almost same at $T_{\mathrm{s}}$ of $620{ }^{\circ} \mathrm{C}$ and $670{ }^{\circ} \mathrm{C}$. Fig. 2(b) shows that the films deposited using DC-FTS apparatus with $\mathrm{Ar}-\mathrm{O}_{2}$ mixture as sputtering gas were composed of the microcrystallites with the $[D]_{(008)}$ of about $200 \mathrm{~nm}$ at $T_{\mathrm{s}}$ of $600{ }^{\circ} \mathrm{C}$ and the ones with that smaller than $100 \mathrm{~nm}$ at $T_{\mathrm{s}}$ of $555^{\circ} \mathrm{C}$. The surface smoothness was very good at $T_{\mathrm{s}}$ of $600{ }^{\circ} \mathrm{C}$, however, it became worse at $T_{\mathrm{s}}$ of $555{ }^{\circ} \mathrm{C}$, which was the critical $T_{\mathrm{s}}$ for forming the BaM crystallites with $c$-axis orientation. The films deposited using DC-FTS apparatus with Xe-Ar- $\mathrm{O}_{2}$ mixture as sputtering gas revealed that their surface smoothness were almost same at $T_{\mathrm{s}}$ of $600{ }^{\circ} \mathrm{C}$ and $475{ }^{\circ} \mathrm{C}$, the latter was the critical temperature. $[D]_{(008)}$ was about 100 $\mathrm{nm}$ at $T_{\mathrm{s}}$ of $600{ }^{\circ} \mathrm{C}$ and was smaller than $100 \mathrm{~nm}$ at $T_{\mathrm{s}}$ of $475{ }^{\circ} \mathrm{C}$.

These results imply that $r$ of the films deposited at small $e\left(V_{\mathrm{p}}-V_{\mathrm{f}}\right)$ and low $T_{\mathrm{s}}$ seems to be large. In the film deposited at small $e\left(V_{\mathrm{p}}-V_{\mathrm{f}}\right)$, using DC-FTS apparatus with $\mathrm{Xe}-\mathrm{Ar}-\mathrm{O}_{2}$ mixture, the crystallites of $\mathrm{BaM}$ firrite tended to grow preferentially along $c$-axis (in the normal direction to the film plane), as shown in Fig. 4(a). $\langle D\rangle_{(008)}$ was almost same value at various $T_{\mathrm{s}}$. On the other hand, the $[D]_{(008)}$ in initial growth layer was as small as $100 \mathrm{~nm}$ at $T_{\mathrm{s}}$ of $475{ }^{\circ} \mathrm{C}$ so that value of $r$ became very large at lower $T_{\mathrm{s}}$.

When the RFDS or DC-FTS apparatus with $\mathrm{Ar}-\mathrm{O}_{2}$ mixture was used the surface of growing film was bombarded with charged particles and recoiled Ar atoms. Since such a heavy bombardment caused the resputtering of $\mathrm{Ba}$ atoms and the deconstruction of BaM crystallites, the elevation of $T_{\mathrm{s}}$ up to the range above $550{ }^{\circ} \mathrm{C}$ was required for reforming the Ba ferrite crystallites with well $c$-axis orientation. The excessive $\mathrm{Fe}$ ions at the film surface seemed to form the spinel crystallites such as $\gamma-\mathrm{Fe}_{2} \mathrm{O}_{3}$ and $\mathrm{Fe}_{3} \mathrm{O}_{4}$ and they were expected to grow with spinel $(\mathrm{mmm})$ orientation because of the small structural difference in spinel $(m m m)$ and $\operatorname{BaM}(008)$ planes. The $(m m m)$ is the most closely-packed plane of oxygen ions in spinel crystallites and they grew preferentially in the direction in $c$-plane. So that the $[D]_{(008)}$ increased with the increase of film thickess and the high $T_{\mathrm{s}}$ also caused the large $[D]_{(008)}$. That the films deposited using DC-FTS apparatus with Ar $-\mathrm{O}_{2}$ mixture exhibited lower $H_{\mathrm{c} \perp}$ than with Xe-Ar- $\mathrm{O}_{2}$ one may be correlated to the surface damage, formation of spinel crystallites and lower $r$.

\section{CONCLUSION}

The microstructure and magnetic characteristics of $\mathrm{Ba}$ ferrite sputtered films were investigated. The films composed of the nanocrystallites with well $c$-axis
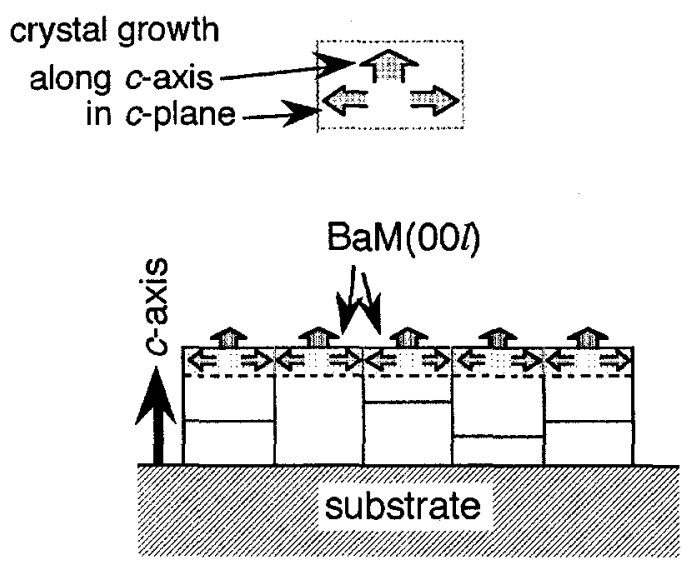

(a) without any bombardments

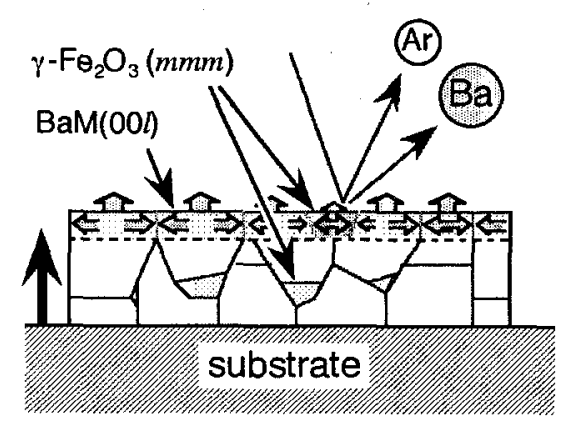

(b) with the bombardment of energetic particles

Fig. 4 Schematic model of crystal growth in the sputterdeposition of Ba ferrite film.

orientation and large aspect ratio $r$ were deposited by suppressing the bombardment of energetic particles to the film surface and by reducing $T_{\mathrm{s}}$ for formation of $\mathrm{BaM}$ crystallites as low as possible. In DC-FTS apparatus, the films with very smooth surface, $[D]_{(008)}$ below $100 \mathrm{~nm}, r$ above 0.4 and $H_{\mathrm{c} \perp}$ as high as $2.3 \mathrm{kOe}$ were deposited at $T_{\mathrm{s}}$ of $475{ }^{\circ} \mathrm{C}$ using the mixture of $\mathrm{Xe}, \mathrm{Ar}$ and $\mathrm{O}_{2}$ as sputtering gas. These films seem to be suitable for the recording layer of ultra-high density perpendicular magnetic media.

\section{ACKNOWLEDGEMENTS}

The authors appreciate the agreement to cite the experimental results by Prof. A. Morisako in Shin-shu University.

\section{REFERENCES}

[1] A. Morisako, M. Matsumoto and M. Naoe, IEEE Trans. on Magn., vol. 22[5], pp. 1146-1148, 1986.

[2] M. Matsuoka, Y. Hoshi, M. Naoe and S. Yamanaka, IEEE Trans. Magn., vol. 18[6], pp. 1119-1121, 1982.

[3] K. Noma, N. Matsushita, S. Nakagawa and M. Naoe, J. Appl. Phys., vol. 79[8], pp. 5970-5972, 1996. 